Article

\title{
Preparation, Characterization, and Release Kinetics of Chitosan-Coated Nanoliposomes Encapsulating Curcumin in Simulated Environments
}

\author{
Mahmoud Hasan, Kamil Elkhoury® ${ }^{\circledR}$, Cyril J. F. Kahn, Elmira Arab-Tehrany * and Michel Linder * \\ Laboratoire D'ingénierie des Biomolécules, Université de Lorraine, EA 4367, France; \\ mahmoud.hasan@univ-lorraine.fr (M.H.); kamil.elkhoury@univ-lorraine.fr (K.E.); \\ cyril.kahn@univ-lorraine.fr (C.J.F.K.) \\ * Correspondences: elmira.arab-tehrany@univ-lorraine.fr (E.A.-T.); michel.linder@univ-lorraine.fr (M.L.); \\ Tel.: +33-3-72-74-41-05 (E.A.-T.); +33-3-72-74-41-05 (M.L.)
}

Academic Editor: Jyh-Ping Chen

Received: 6 May 2019; Accepted: 22 May 2019; Published: 27 May 2019

check for updates

\begin{abstract}
Curcumin, a natural polyphenol, has many biological properties, such as anti-inflammatory, antioxidant, and anti-carcinogenic properties, yet, its sensitivity to light, oxygen, and heat, and its low solubility in water renders its preservation and bioavailability challenging. To increase its bioaccessibility, we fabricated nanoliposomes and chitosan-coated nanoliposomes encapsulating curcumin, and we evaluated the systems in terms of their physicochemical characteristics and release profiles in simulated gastrointestinal mediums. Chitosan-coating enhanced the stability of nanoliposomes and slowed the release of curcumin in the simulated gastrointestinal (GI) environment. This study demonstrates that nanoliposomes and chitosan-coated nanoliposomes are promising carriers for poorly soluble lipophilic compounds with low oral bioavailability, such as curcumin.
\end{abstract}

Keywords: chitosan; nanoliposomes; curcumin; release kinetics; gastrointestinal environment

\section{Introduction}

Curcumin, extracted and purified from ground rhizomes of Curcuma longa, presents antioxidant [1-3], wound healing [4,5], anticancer [6-8], antimicrobial [9-11], and anti-inflammatory [12-14] properties. However, studies showed that this natural remedy presents low bioavailability as extremely low serum concentrations have been detected in the human serum after oral administration [15-17]. This can be attributed to the poor aqueous solubility of curcumin, fragmentation at physiological $\mathrm{pH}$, and rapid hydrolysis [18].

Various delivery systems have been proposed to improve the bioavailability and the therapeutic efficacy of curcumin, such as polymer nanoparticles [19,20], lipid-based nanoparticles [21,22], and inorganic nanoparticles [23]. Liposomes are one of the oldest and most widely used lipid-based delivery carriers, due to their low toxicity, their biocompatibility, and non-immunogenicity [24]. These nanovehicles are broadly used to overcome physiological barriers and deliver drugs to cells and tissues $[25,26]$. They are able to encapsulate poorly soluble molecules and enable their administration in aqueous mediums [27]. These features are presented by liposomes thanks to their main constituents, phospholipids, which are responsible for the liposome structure resemblance to cell membranes $[28,29]$. Phospholipids are amphiphilic molecules composed of a hydrophilic head and a hydrophobic tail. Their amphiphilic property allows the self-sealing of liposomes, which renders them an ideal delivery system in aqueous media and has various applications in the cosmetic [30], food [31], pharmaceutical [32], and tissue engineering $[33,34]$ fields. 
Lecithin, from which liposomes can be produced, possesses two long hydrocarbon chains and is a major component of lipid bilayers in cell membranes. Moreover, due to its biodegradability, lecithin is considered as an ideal biological surfactant [35]. Numerous in vivo studies have proved that the n-3 series polyunsaturated fatty acids (PUFAs), especially docosahexaenoic acid (DHA, 22:6n-3) and eicosapentaenoic acid (EPA, 20:5 n-3), are important to various physiological processes, which are present in high concentrations in lecithin from the salmon head [36-39].

Destruction in the gastrointestinal tract by $\mathrm{pH}$, pancreatic lipase, and bile salts, presents the biggest challenge for liposomal delivery systems [40]. Previous studies have analyzed the effects of coating liposomes with a polymeric membrane to minimize these effects [41,42]. Several studies have investigated the coating of liposomes with chitosan [42-44]. The positively charged chitosan forms an ionic bond with negatively charged liposomes to create the chitosan-coated liposomes [45]. Coating these nanovesicles with chitosan renders them mucoadhesive and increases their stability $[45,46]$. By combining chitosan and liposomal characteristics, specific, prolonged, and controlled release may be achieved [47]. Because of its bioadhesivity, low toxicity, permeation enhancing properties, hydrophilicity, biocompatibility, and biodegradability, chitosan has received substantial attention in novel drug delivery systems, aimed at improving the bioavailability of drugs at the targeted site of absorption [48].

The present study focused on the preparation and physicochemical characterization of chitosan-coated nanoliposomes produced from salmon-extracted lecithin. Additionally, and more importantly, the release kinetics of encapsulated curcumin inside the coated system in simulated gastric and intestinal digestion environments was investigated.

\section{Results and Discussion}

\subsection{Fatty Acid Analyses}

Table 1 presents the purified salmon phospholipids' main fatty acid compositions. The total polyunsaturated fatty acids in salmon phospholipids were predominate $(48.72 \%)$. This percentage was followed by the saturated fatty acids percentage (27.67\%). C20:5 n-3 (8.83\%) and C22:6 n-3 (28.15\%) in the polyunsaturated fatty acids class, C16:0 (29.33\%) in the saturated fatty acids class, and C18:1 n-9 $(19.12 \%)$ in the monounsaturated fatty acids class were the main proportions of fatty acids. The ratio of n-3/n-6 was 8.73, and DHA/EPA was 3.19.

\subsection{Lipid Classes}

Thin-layer chromatography (Iatroscan) was used to separate the lipid classes of salmon phospholipids. The major class of phospholipids was phosphatidylcholine $(40.49 \%)$, followed by phosphatidylinositol $(15.25 \%)$, and phosphatidylserine $(7.95 \%)$. It is interesting to note that phospholipids can enhance drug flux; they are called a sorption promoter [49]. The percentage of polar lipid in salmon phospholipids was 100\%, whereas it did not contain any triglycerides or other nonpolar lipids.

\subsection{Physicochemical Characterization}

Lipid composition and preparation methods can affect nanoliposome particles size [50]. Immediately after their preparation, nanoliposomes average particle size was measured. The mean size of the uncoated nanoliposomes was $115.8 \pm 3.5 \mathrm{~nm}$ and increased to $330.4 \pm 5.1 \mathrm{~nm}$ after coating with chitosan. The size of the nanoliposomes encapsulating curcumin $(114.9 \pm 1.8 \mathrm{~nm})$ was equal to the size of empty nanoliposomes. Similarly, chitosan-coated curcumin-loaded nanoliposomes size $(324.7 \pm 2.2 \mathrm{~nm})$ was similar to the unloaded coated nanoparticles size. This suggested that the curcumin encapsulation had minimal effect on the coated and uncoated nanoparticle size. 
Table 1. Fatty acid compositions, after purification by acetone precipitation, of salmon phospholipids.

\begin{tabular}{|c|c|c|}
\hline \multirow{2}{*}{$\begin{array}{c}\text { Fatty Acids } \\
\text { C14 }\end{array}$} & \multicolumn{2}{|c|}{$\begin{array}{c}\text { Salmon Phospholipids } \\
\text { \% SD }\end{array}$} \\
\hline & 2.24 & 0.04 \\
\hline C15 & 0.28 & 0.00 \\
\hline $\mathrm{C} 16$ & 19.33 & 0.21 \\
\hline $\mathrm{C} 17$ & 0.55 & 0.02 \\
\hline $\mathrm{C} 18$ & 4.47 & 0.03 \\
\hline $\mathrm{C} 20$ & 0.22 & 0.02 \\
\hline $\mathrm{C} 22$ & 0.58 & 0.01 \\
\hline SFA & 27.67 & \\
\hline C16:1n7 & 1.83 & 0.02 \\
\hline C18:1n9 & 19.11 & 0.29 \\
\hline C20:1n9 & 0.28 & 0.01 \\
\hline C22:1n9 & 2.39 & 0.00 \\
\hline MUFA & 23.61 & \\
\hline C18:2n6 & 4.41 & 0.07 \\
\hline C18:3n3 & 1.98 & 0.05 \\
\hline C20:4n6 & 2.84 & 0.04 \\
\hline C20:5n3(EPA) & 8.83 & 0.02 \\
\hline $\mathrm{C} 22: 5 \mathrm{n} 3$ & 2.51 & 0.10 \\
\hline C22:6n3(DHA) & 28.15 & 0.19 \\
\hline PUFA & 48.72 & \\
\hline$n-3 / n-6$ & 10.06 & \\
\hline DHA/EPA & 3.19 & \\
\hline
\end{tabular}

The polydispersity index (PDI) is a dimensionless measure of particle size distribution, also measured by dynamic light scattering (DLS) [51]. Figure 1 shows that PDIs of all formulations were between 0.27 and 0.31 , which indicates that particles had a controlled size distribution and a narrow dispersity.

$\zeta$-potential measurements characterize the particles' surface electrical charge [52]. The greater the $\zeta$-potential magnitude, the greater the repulsion between particles, and thus the, more stable the colloidal dispersions [53]. Coating the empty and loaded nanoliposomes with chitosan (Figure 1) shifted the $\zeta$-potential from negative $(-44.1 \pm 1.1 \mathrm{mV}$ and $-50.8 \pm 3.1 \mathrm{mV})$ to positive values $(+56.3 \pm 1.59 \mathrm{mV}$ and $+60 \pm 1.3 \mathrm{mV}$ ), respectively. Chitosan-coating led to a higher positive $\zeta$-potential magnitude, which suggests that the coating increased the stability of nanoliposomes

The polymer-liposome interactions caused an increase in particle size and $\zeta$-potential of nanoparticles, which reflects several changes in their surface properties.

With respect to the formulation stability with time, no significant variation in particle size of uncoated and chitosan-coated nanoliposomes, encapsulating curcumin or not, was observed over 30 days of incubation at 4 and $37^{\circ} \mathrm{C}$. 

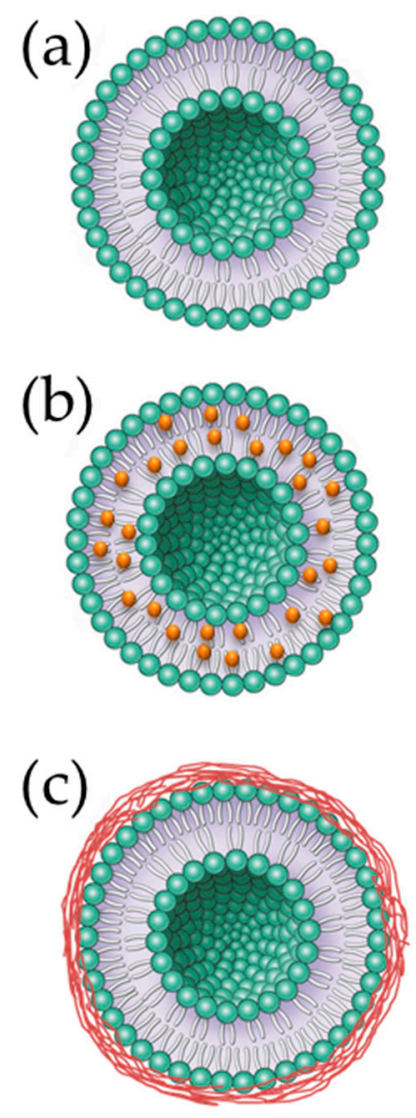

(d)

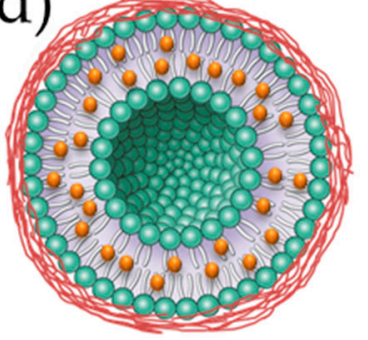

${ }^{10}$ Size: $115.8 \pm 3.5 \mathrm{~nm}$
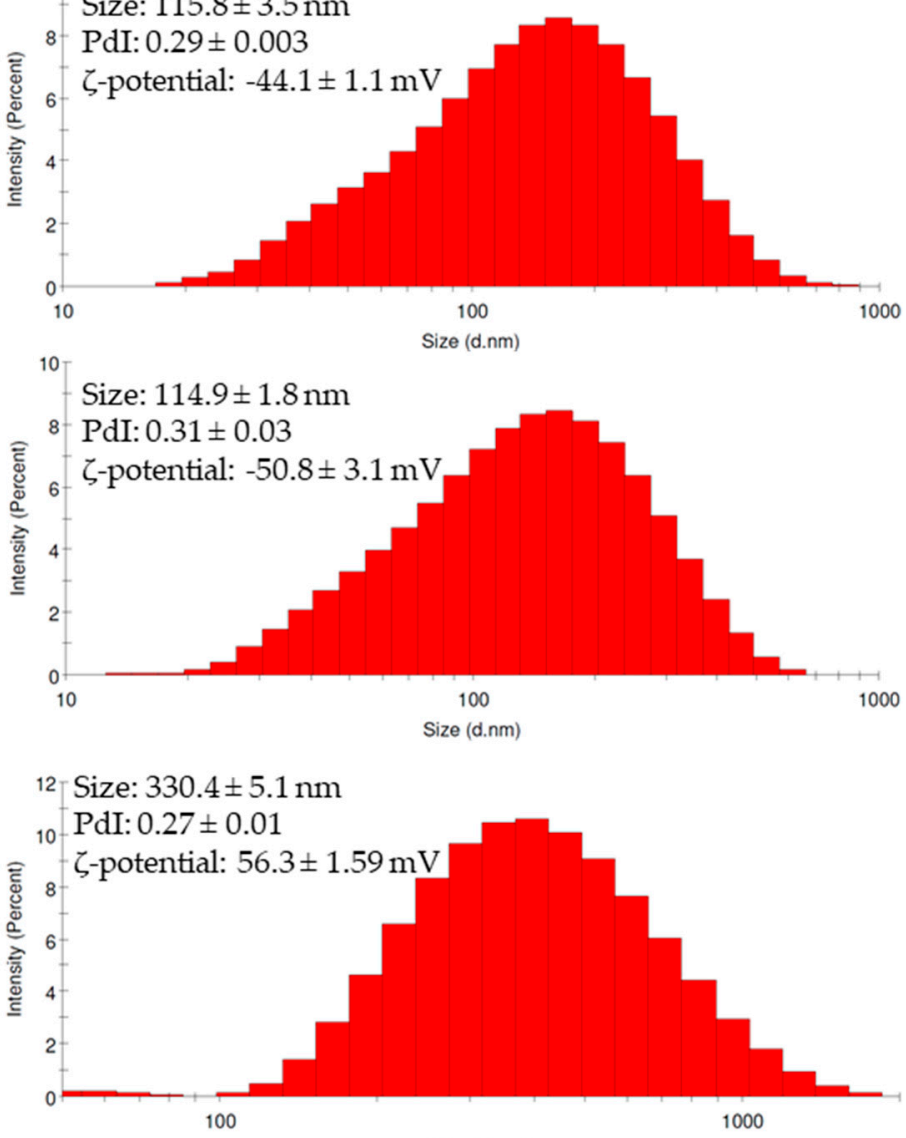

Size (d.nm)

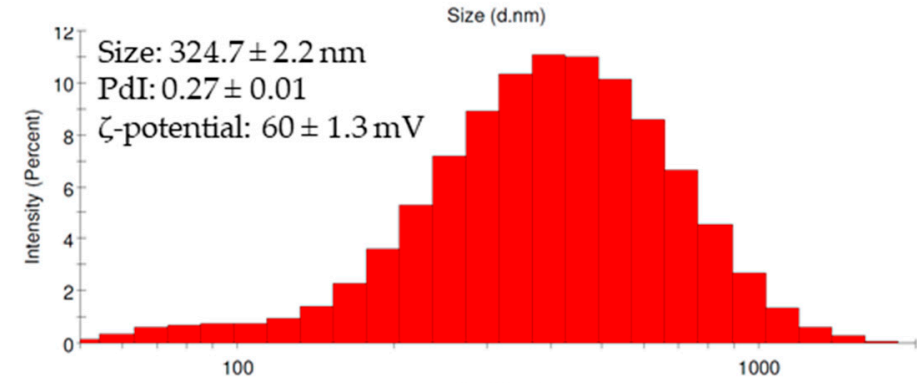

Size (d.nm)

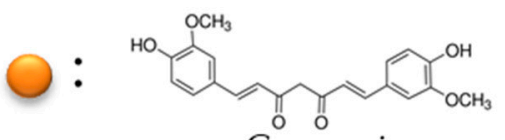

Curcumin

Figure 1. Schematic and physicochemical characterization of (a) nanoliposomes, (b) curcumin-loaded nanoliposomes, (c) chitosan-coated nanoliposomes, and (d) curcumin-loaded nanoliposomes coated with chitosan.

\subsection{Entrapment Efficiency}

Curcumin entrapment efficiency in salmon nanoliposomes was $78.2 \pm 0.5 \%$, which was greater than our previous results $(67.3 \pm 1.1 \%$ [8]), due to a change in the loading method. In this study, we loaded the nanoliposomes using the thin film method, where we solubilized the phospholipids and curcumin in a chloroform/methanol mixture (2:1 $v / v)$, before evaporating it using a Rotavapor. This increased the distribution of curcumin in the phospholipids and hence increased the entrapment efficiency. 
Moreover, the encapsulation efficiency of curcumin significantly increases when nanoliposomes are coated with chitosan, with an entrapment efficiency of $95.2 \pm 1.2 \%$.

\subsection{In Vitro Drug Release}

\subsubsection{Release in PBS Solution}

Curcumin encapsulated in uncoated and chitosan-coated nanoliposomes was incubated at $37^{\circ} \mathrm{C}$ in PBS, and it's in vitro release behavior was studied over four hours and is presented as a cumulative release percentage in Figure 2. A biphasic release profile was observed for all formulations. A biphasic release profile is composed of an immediate drug release followed by a sustained release [54]. The biphasic delivery system helps in overcoming multiple dosing regimen problems [55].
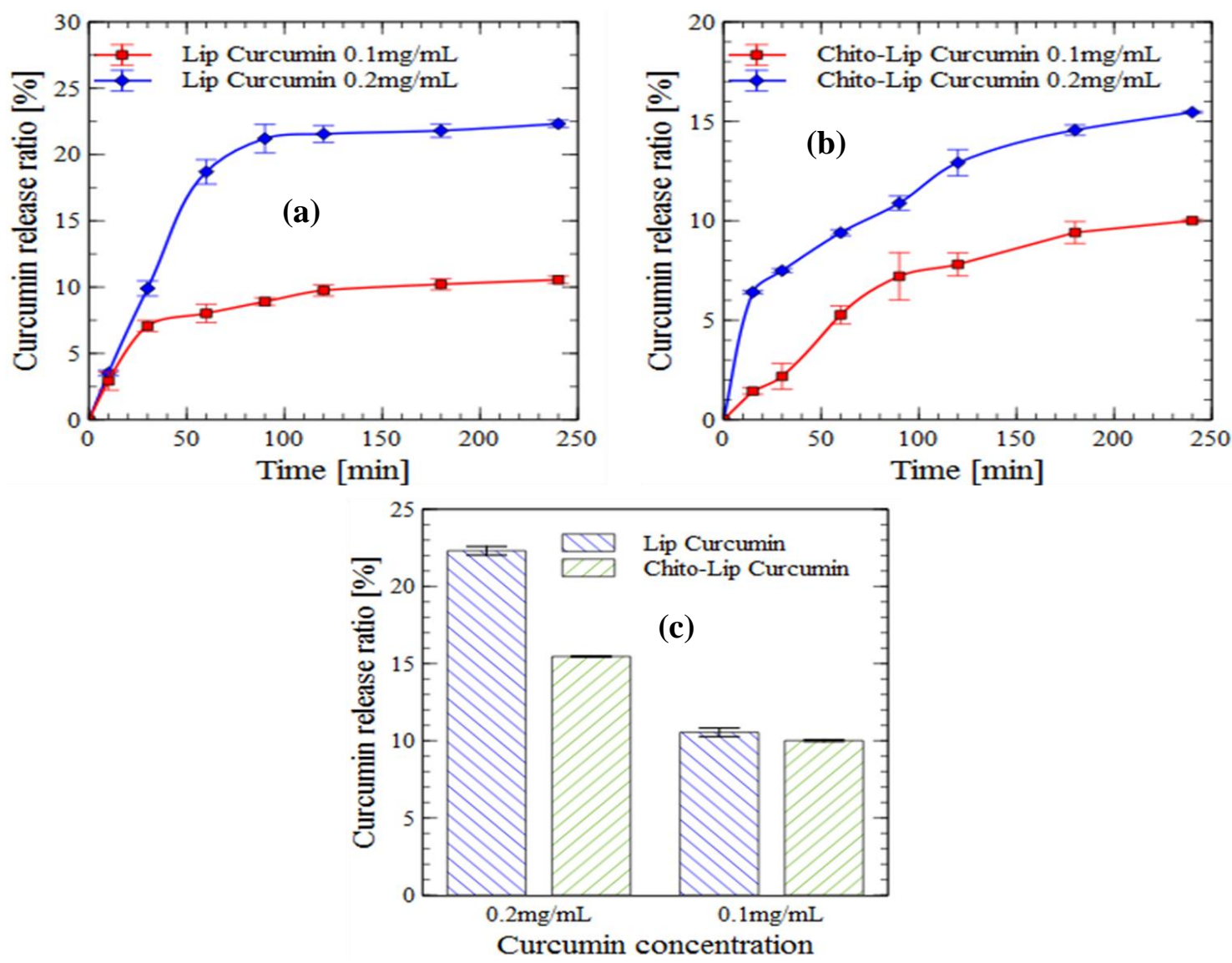

Figure 2. In vitro release (PBS solution) of curcumin encapsulated in nanoliposomes (a) and chitosan-coated nanoliposomes (b) (values reported are mean $\pm \mathrm{SD} ; n=3$ ), and the proportions of released curcumin from nanoliposomes and chitosan-coated nanoliposomes after four hours of incubation $(\mathbf{c})$.

In the case of uncoated nanoliposomes charged with $0.2 \mathrm{mg} / \mathrm{mL}$ curcumin, a fast release $(18 \%)$ was observed at the end of the first hour, followed by a sustained release $(22.3 \%)$ over the remaining three hours. The initial burst release decreased, releasing only $10 \%$ of the encapsulated drug for a curcumin concentration of $0.2 \mathrm{mg} / \mathrm{mL}$, and the sustained release of curcumin from the colloid particles was more pronounced.

The initial burst release is caused by the release of the drug entrapped near the surface, whereas the sustained release is the result of the diffusion and release of the drug from the nanoliposome core. In the case of coated nanoliposomes, the biphasic release behavior is affected by the presence of the chitosan layer, formed via electrostatic interactions between the positive ammonium groups of chitosan 
and the negatively charged phosphate groups of the nanoliposomes, as previously determined by Fourier-transform infrared spectroscopy (FTIR) analysis [44]. This coating layer will probably form a diffusion obstacle for the drug released from the surface, resulting in a slower release [56]. Furthermore, the coating of nanoliposomes with chitosan causes a decrease in membrane fluidity, which is crucial in the release behavior of the entrapped drug [44,57].

In respect to the concentration of loaded curcumin, we observed that the release profile of curcumin was almost similar for both concentrations of 0.1 and $0.2 \mathrm{mg} / \mathrm{mL}$ of the chitosan-coated particles. However, their difference in release profiles was noticeable for uncoated nanoliposomes. Therefore, these results imply that the release profile of core material from the nanocarrier systems is significantly affected and can be tuned by applying a polymer coating.

\subsubsection{Gastric Digestion}

The in vitro release profiles of curcumin from uncoated nanoliposomes and chitosan-coated liposomes in a simulated gastric digestion environment are presented in Figure 3. The results indicated that encapsulated curcumin was well protected by nanoliposomes from pepsin action. Over $80 \%$ of curcumin was retained in uncoated nanoliposomes and about $90 \%$ for the chitosan-coated liposome during simulated gastric digestion (four hours). Drug release percentage in the simulated gastric fluid (SGF) decreased for chitosan-coated nanoliposomes, which is a desirable attribute to protect the bioactive molecule from the severe gastric environment [58,59].
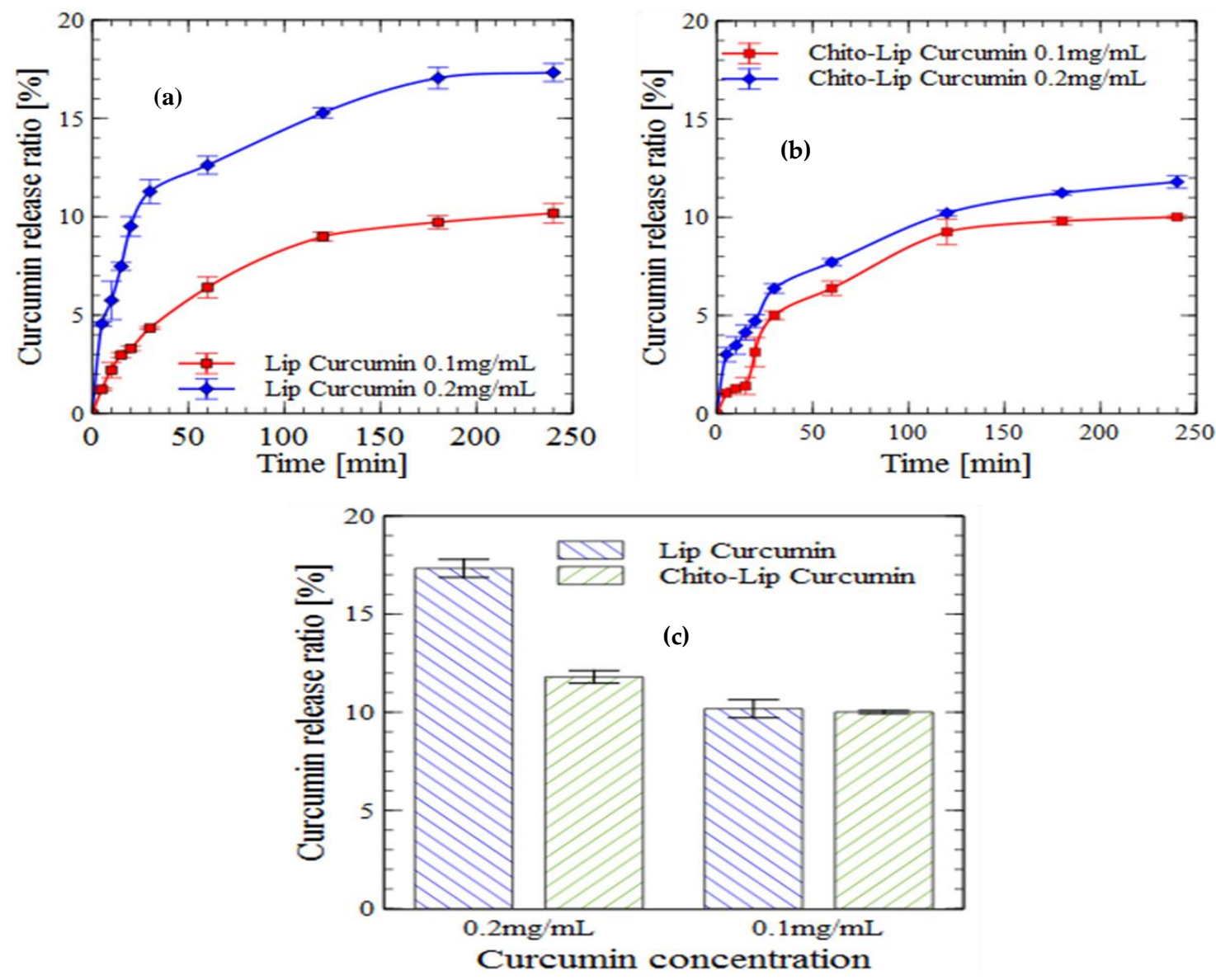

Figure 3. In vitro release (gastric digestion) of curcumin encapsulated in nanoliposomes (a) and chitosan-coated nanoliposomes (b) (values reported are mean $\pm \mathrm{SD} ; n=3$ ), and the proportions of released curcumin from nanoliposomes and chitosan-coated nanoliposomes after four hours of incubation (c). 
Release profiles of curcumin during gastric incubation were almost similar to their profiles in the PBS solution, with a slight decrease especially for uncoated nanoliposomes, for which the maximum curcumin released after four hours of incubation was $23.3 \%$ in PBS and $17.33 \%$ in the simulated gastric environment.

\subsubsection{Intestinal Digestion}

The curcumin release rate from loaded-nanoliposomes was higher in simulated intestinal fluid (SIF), a mixture of pancreatin and bile salts, than in SGF, which was also found in previous studies [60-62]. Liu et al. suggested that, under SIF conditions, this behavior is caused by the pancreatic enzyme that disrupts the liposomal membrane [62].

A biphasic release was also observed, especially in the case of uncoated nanoliposomes charged with $0.2 \mathrm{mg} / \mathrm{mL}$ curcumin, presenting a rapid release of about $24.5 \%$ at the end of the first $30 \mathrm{~min}$, that was followed by a sustained release of around $29.5 \%$ over four hours (Figure 4 ).
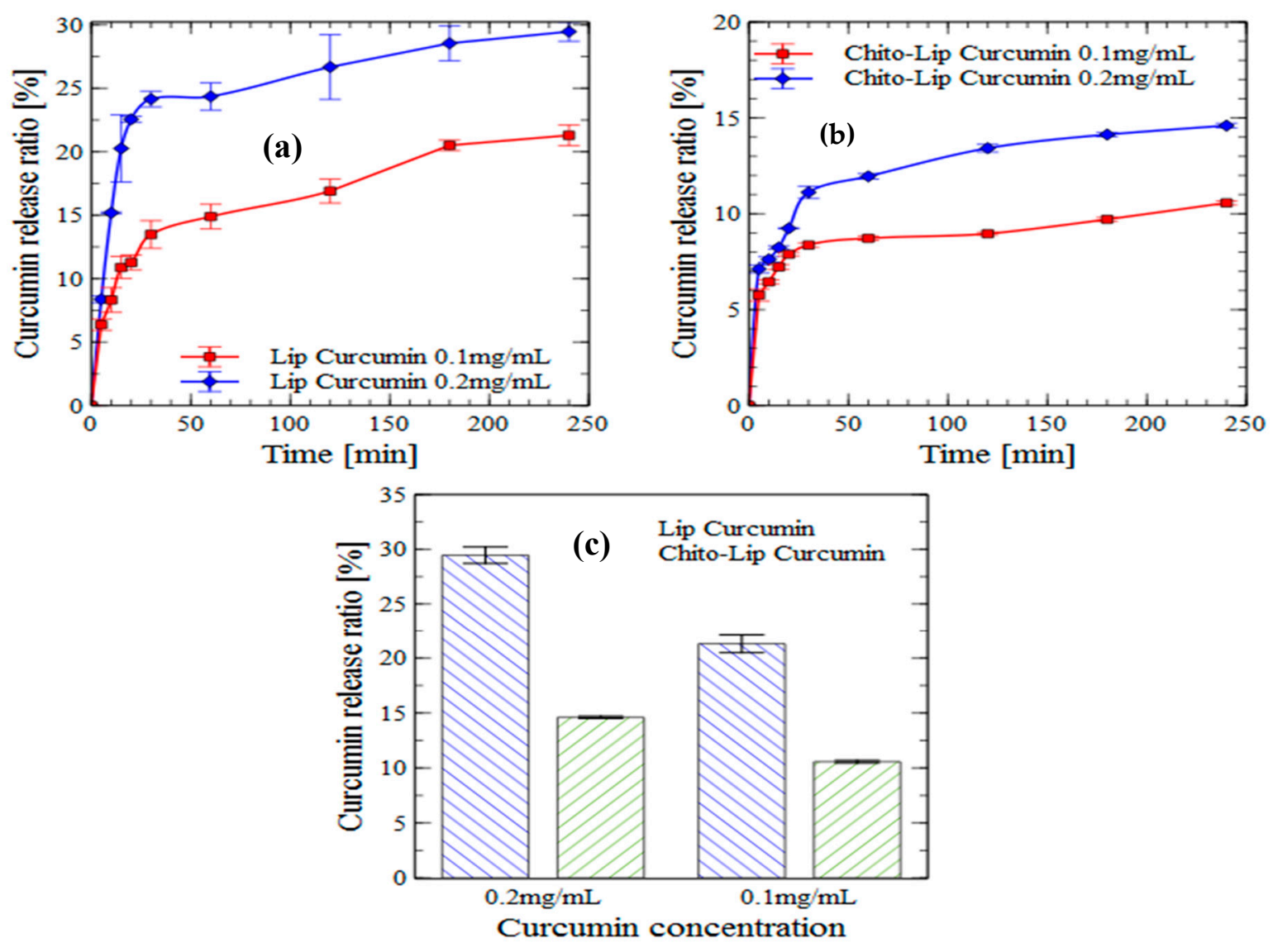

Figure 4. In vitro release (intestinal digestion) of curcumin encapsulated in nanoliposomes (a) and chitosan-coated nanoliposomes (b) (values reported are mean $\pm \mathrm{SD} ; n=3$ ), and the proportions of released curcumin from nanoliposomes and chitosan-coated nanoliposomes after four hours of incubation (c).

Curcumin was released in a controlled manner for longer durations. These results suggest that loaded nanoliposomes can be parenterally administered, thus avoiding the harsh gastrointestinal route and control the release of the low bioavailable curcumin.

To improve their stability and to target specific areas in the body, the liposomal surface can be modified $[63,64]$. One possible modification is the coating with chitosan, which can increase nanoliposomes stability in SGF and SIF, and improve their encapsulated drug solubility and mucoadhesive properties [65]. 
Determining curcumin release from chitosan-coated liposome in SIF is challenging because of the precipitation of chitosan at $\mathrm{pH} 6.8$ [66]. For this reason, we added $0.5 \%$ Tween- 80 in SIF in order to solubilize the released curcumin during the digestion.

The curcumin release rate from all nanoliposome formulations was higher in the simulated intestinal fluid than in the simulated gastric fluid. Moreover, the release was much lower when the chitosan coating was applied, which might be due to the fact that polysaccharides have the capacity to inhibit lipid digestion $[67,68]$.

Despite the chitinase and chitotriosidase activities of the pancreatic enzyme, it is better to complete the simulated digestion in the presence of other enzymes, such as beta-glucosidase and rat or human colonic enzymes, as chitosan will be degraded predominantly by lysozymes and bacterial enzymes in the colon [69-72].

\section{Materials and Methods}

Chitosan, with a deacetylation degree up to $75 \%$ prepared from shrimp shells, curcumin, boron trifluoride (14\% in methanol), acetonitrile ( $\geq 99.9 \%)$, chloroform ( $\geq 99.9 \%)$, methanol $(\geq 99.9 \%)$, and hexane $(\geq 99.9 \%)$ were all purchased from Fisher (France) and Sigma-Aldrich (France). Acetic acid $(\geq 99.8 \%)$ was supplied by Prolabo-VWR. Salmo salar were enzymatically hydrolyzed to obtain lecithin in an organic solvent-free extraction, as previously described by Linder et al. [73].

\subsection{Fatty Acids Composition}

Fatty acid methyl esters (FAMEs) were analyzed as previously described [74]. FAMEs separation was carried out on gas chromatography (Perichrom, Saulx-lès-Chartreux, France). Injector and detector temperatures were fixed at $250{ }^{\circ} \mathrm{C}$. The column temperature was initially set at $120^{\circ} \mathrm{C}$ for three min, then it was increased to $180{ }^{\circ} \mathrm{C}$ at a rate of $2{ }^{\circ} \mathrm{C} \cdot \mathrm{min}^{-1}$ and kept at $220^{\circ} \mathrm{C}$ for $25 \mathrm{~min}$. Standard mixtures (Supelco, Sigma-Aldrich, Bellefonte, PA, USA) were used to categorize fatty acids. All runs were performed in triplicate.

\subsection{Lipid Classes}

Lipid classes of salmon phospholipids were determined by an Iatroscan (MK-5 TLC-FID, Iatron Laboratories Inc., Tokyo, Japan) as described in detail previously [8]. Two migrations were executed to characterize the proportion of polar and neutral lipid fractions. Area percentages were shown as the average of three repetitions.

\subsection{Nanoliposomes Preparation and Coating}

Loaded nanoliposomes and chitosan-coated nanoliposomes have been prepared as described previously [44]. In a completely dry round-bottomed flask, $1.5 \mathrm{~g}$ of salmon phospholipid dissolved in $30 \mathrm{~mL}$ of chloroform and $10 \mathrm{mg}$ of curcumin dissolved in $15 \mathrm{~mL}$ of methanol were mixed. Organic solvents were completely evaporated using a Rotavapor under vacuum, and a thin lipid film was formed on the flask wall. $47.5 \mathrm{~mL}$ of ultrapure water was then added, and the suspension was agitated for four hours under nitrogen. To produce nanoliposomes, the suspension was sonicated at $40 \mathrm{kHz}$ for five $\min (1 \mathrm{~s}$ on, $1 \mathrm{~s}$ stop) in an ice bath.

To form the coated nanoliposomes, $0.5 \mathrm{~g}$ of chitosan and $0.5 \mathrm{~mL}$ of acetic acid were added to the solution already prepared before sonication. The suspension was then agitated under the same conditions for $4-5 \mathrm{~min}$. Sonication at $40 \mathrm{kHz}$ for five $\min$ ( $1 \mathrm{~s}$ on, $1 \mathrm{~s}$ stop) in an ice bath was first applied, followed by homogenization using a high-pressure homogenizer (EmulsiFlex-C3). The mixture was introduced under a pressure of 1500 bar in quantities of $50 \mathrm{~mL}$ for $7-8$ cycles.

Uncoated and Chitosan-coated nanoliposome samples were stored in glass bottles in the dark at 4 and $37^{\circ} \mathrm{C}$. 


\subsection{Size and $\zeta$-Potential Measurements}

The size, PDI, and $\zeta$-potential of nanoliposomes were measured by DLS (Malvern Zetasizer Nano ZS, UK) following the dilution of samples (1:200) using ultrapure water. Samples were analyzed in standard capillary electrophoresis cells to measure their $\zeta$-potential. Size and $\zeta$-potential measurements were studied with an absorbance of 0.01 , a fixed scattering angle of $173^{\circ}$, a refractive index of 1.471 , and at $25^{\circ} \mathrm{C}$. Measurements were completed in triplicate.

\subsection{Stability of Nanoliposomes and Chitosan-Coated Nanoliposomes}

Uncoated and chitosan-coated nanoliposomes, both empty or encapsulating curcumin, were stored in a drying room for 30 days at 4 and $37^{\circ} \mathrm{C}$. Physicochemical characterization of all formulations was examined every three days.

\subsection{Entrapment Efficiency}

The percentage of curcumin encapsulated was determined by centrifuging the coated and uncoated nanoliposomes encapsulating curcumin at $9000 \times g$ for $15 \mathrm{~min}$. After centrifugation, the supernatant was dissolved in methanol to erupt the nanoliposomes and release the entrapped curcumin. The concentration of encapsulated curcumin was measured by an HPLC system (Shimadzu, Kyoto, Japan) at $425 \mathrm{~nm}$ equipped with a Zorbex SB-C18 column $(5 \mu \mathrm{m}, 4.6 \mathrm{~mm} \times 250 \mathrm{~mm})$. The suspension was quantified in an isocratic mode using acetonitrile $(v / v, 65 \%)$, acetic acid $2 \%(v / v, 30 \%)$, and methanol $(v / v, 5 \%)$ at a flow rate of $0.5 \mathrm{~mL} \cdot \mathrm{min}^{-1}$. Experiments were performed in triplicate.

Entrapment efficiency was calculated according to the following equation:

$$
\text { EE }(\%)=(\text { Initial drug }- \text { Free drug }) /(\text { Initial drug }) \times 100,
$$

\subsection{In Vitro Drug Release}

\subsubsection{Release in PBS Solution}

Curcumin released percentages were determined as previously described [75]. In brief, nanoliposomes encapsulating curcuminoids were dispersed in PBS (pH 7.4) at a ratio of 1:2 and free curcuminoid molecules were removed via centrifugation at $9000 \times g$ for $15 \mathrm{~min}$. All formulations were equally separated into 24 aliquots of $1.8 \mathrm{~mL}$ in Eppendorf tubes and stored in a water bath at $37^{\circ} \mathrm{C}$. Because of the low curcumin solubility in an aqueous medium, released crystals precipitated at the bottom of the tubes. The sample was centrifuged at $9000 \times g$ for $15 \mathrm{~min}$ to separate the released curcuminoid crystals from the loaded nanoliposome, at predetermined time intervals. After centrifugation, released curcumin crystals aggregated in the pellet and the supernatant containing the loaded nanoliposomes was assayed by HPLC at $425 \mathrm{~nm}$ after dissolution with methanol to determine the amount of encapsulated curcuminoids. All experiments were carried out in triplicate.

The percentage of released curcuminoids was determined using the formula:

$$
\% \text { Drug release }=(\text { Released Curcuminoids/Encapsulated Curcuminoids }) \times 100,
$$

\subsubsection{Simulated Gastric Digestion}

SGF which virtually mimics the stomach conditions was constituted as described earlier with slight modification [76]. Briefly, after removing free curcuminoids molecules via centrifugation at $9000 \times g$ for $15 \mathrm{~min}$. Samples were added to the SGF $(0.2 \mathrm{wt} . \% \mathrm{NaCl}$, pepsin $0.32 \mathrm{wt} . \%$ (from porcine stomach mucosa), $\mathrm{pH} 2$ ), and the $\mathrm{pH}$ was adjusted to 2 with $0.5 \mathrm{M} \mathrm{HCl}$.

Curcumin-loaded nanoliposomes (adjusted to $\mathrm{pH}$ 2) were mixed with SGF at a ratio of 1:2 in a flask. The mixture was placed in a shaking water bath $(170 \mathrm{rpm})$ at $37^{\circ} \mathrm{C}$. Samples were collected at different time intervals, and the digestion was stopped by placing the Eppendorf tubes in cold water 
for $15 \mathrm{~min}$, then the released curcumin was measured using the same method for PBS explained earlier. All experiments were carried out in triplicate.

\subsubsection{Simulated Intestinal Digestion}

The same preparation method of SIF described before was used with slight modifications $[77,78]$. Part of the juice obtained after digestion in SGF for two hours, which is the normal duration of GI transit, was incubated in SIF containing $(30 \mathrm{mM} \mathrm{CaCl} 2,1.0 \mathrm{wt} . \%$ Pancreatin (from porcine pancreas), $0.5 \mathrm{wt} . \%$ Bile salts, and $25 \mathrm{mM}$ potassium dihydrogen phosphate, $\mathrm{pH} 6.8$ ). The $\mathrm{pH}$ was adjusted to 6.8 with $0.5 \mathrm{M} \mathrm{NaOH}$.

The mixture was placed in a shaking water bath $(170 \mathrm{rpm})$ at $37^{\circ} \mathrm{C}$. The samples were pipetted out from the flask at predetermined time intervals, and the Eppendorf tubes were immediately put in an ice-cold water bath for $15 \mathrm{~min}$ to stop the further hydrolysis. Then, the released drug was determined using the same method for PBS explained above, and all the experiments were carried out in triplicate.

In the case of chitosan-coated liposomes, the solution was added to SIF $0.5 \%(w / v)$ Tween-80 to solubilize free-released curcumin [63], then the same digestive conditions were followed. The samples were centrifuged first at $9000 \times g$ for $15 \mathrm{~min}$ to eliminate the precipitated particles, then the supernatant which contains the free curcumin dissolved in Tween- 80 solution was separated by centrifugation at $3300 \times g$ for 20 min using a membrane filter (Centrisart ${ }^{\circledR}$ I, MWCO $100 \mathrm{kDa}$; Sartorius, GmbH Germany) [79].

\section{Conclusions}

Curcumin is highly unstable and hydrophobic, which makes its oral administration challenging. For this reason, curcumin was encapsulated in nanoliposomes and chitosan-coated nanoliposomes. The $\zeta$-potential of the empty and loaded nanoliposomes changed to an increasingly positive value for the chitosan-coated compared to a negative value for the uncoated nanoliposomes.

The results presented in this study proved that curcumin was released in a controlled manner from all nanoliposome formulations under simulated digestion. Moreover, the curcumin release rate from all nanoliposome formulations was higher in SIF than in SGF.

Chitosan-coated nanoliposomes exhibited a more stable and prolonged release of curcumin in comparison to uncoated nanoliposomes, especially in SGF. The results, presented in this study, demonstrate that chitosan-coated nanoliposomes might be an efficient drug delivery system for the oral delivery of curcumin.

Author Contributions: Conceptualization-M.H.; Methodology-M.H., C.J.F.K. and M.L.; Software-M.H. and K.E.; Validation-E.A.-T. and M.L.; Formal Analysis-M.H., and K.E.; Investigation-M.H. and K.E.; Resources-E.A.-T. and M.L.; Data Curation-M.H. and K.E.; Writing of Original Draft Preparation-M.H. and K.E.; Writing, Review, and Editing-K.E. and E.A.-T.; Visualization-K.E., C.J.F.K. and E.A.T.; Supervision-M.L. and E.A.-T.; Project Administration-M.L. and E.A.-T.; Funding Acquisition-M.L. and E.A.T.

Funding: This research received no external funding.

Acknowledgments: M.H. acknowledges support from the Syrian Ministry of Higher Education and Aleppo-University. K.E. acknowledges support from the French Ministry of Higher Education, Research and Innovation.

Conflicts of Interest: The authors declare no conflict of interest.

\section{Abbreviations}

$\begin{array}{ll}\text { SFA } & \text { Saturated fatty acids; } \\ \text { MUFA } & \text { Monounsaturated fatty acids; } \\ \text { PUFA } & \text { Polyunsaturated fatty Acids; } \\ \text { EPA } & \text { Eicosapentaenoic acid; } \\ \text { DHA } & \text { Docosahexaenoic Acid; } \\ \text { n-3 } & \text { Omega-3 fatty acids; } \\ \text { n-6 } & \text { Omega-6 fatty acids. }\end{array}$




\section{References}

1. Alisi, I.O.; Uzairu, A.; Abechi, S.E.; Idris, S.O. Evaluation of the antioxidant properties of curcumin derivatives by genetic function algorithm. J. Adv. Res. 2018, 12, 47-54. [CrossRef] [PubMed]

2. Dhir, A. Curcumin in epilepsy disorders: Curcumin and Epilepsy. Phytother. Res. 2018, 32, $1865-1875$. [CrossRef]

3. Babu, A.; Mohammed, S.; Harikumar, K.B. Antioxidant Properties of Curcumin: Impact on Neurological Disorders. In Curcumin for Neurological and Psychiatric Disorders; Elsevier: Thiruvananthapuram, India, 2019; pp. 155-167, ISBN 978-0-12-815461-8.

4. Barchitta, M.; Maugeri, A.; Favara, G.; Magnano San Lio, R.; Evola, G.; Agodi, A.; Basile, G. Nutrition and Wound Healing: An Overview Focusing on the Beneficial Effects of Curcumin. IJMS 2019, $20,1119$. [CrossRef]

5. Akbik, D.; Ghadiri, M.; Chrzanowski, W.; Rohanizadeh, R. Curcumin as a wound healing agent. Life Sci. 2014, 116, 1-7. [CrossRef]

6. Tomeh, M.; Hadianamrei, R.; Zhao, X. A Review of Curcumin and Its Derivatives as Anticancer Agents. IJMS 2019, 20, 1033. [CrossRef]

7. Suhito, I.R.; Lee, W.; Baek, S.; Lee, D.; Min, J.; Kim, T.-H. Rapid and sensitive electrochemical detection of anticancer effects of curcumin on human glioblastoma cells. Sens. Actuators B Chem. 2019, 288, 527-534. [CrossRef]

8. Hasan, M.; Belhaj, N.; Benachour, H.; Barberi-Heyob, M.; Kahn, C.J.F.; Jabbari, E.; Linder, M.; Arab-Tehrany, E. Liposome encapsulation of curcumin: Physico-chemical characterizations and effects on MCF7 cancer cell proliferation. Int. J. Pharm. 2014, 461, 519-528. [CrossRef]

9. Panahi, Y.; Fazlolahzadeh, O.; Atkin, S.L.; Majeed, M.; Butler, A.E.; Johnston, T.P.; Sahebkar, A. Evidence of curcumin and curcumin analogue effects in skin diseases: A narrative review. J. Cell. Physiol. 2019, 234, 1165-1178. [CrossRef]

10. Gómez-Estaca, J.; Balaguer, M.P.; López-Carballo, G.; Gavara, R.; Hernández-Muñoz, P. Improving antioxidant and antimicrobial properties of curcumin by means of encapsulation in gelatin through electrohydrodynamic atomization. Food Hydrocoll. 2017, 70, 313-320. [CrossRef]

11. Krausz, A.E.; Adler, B.L.; Cabral, V.; Navati, M.; Doerner, J.; Charafeddine, R.A.; Chandra, D.; Liang, H.; Gunther, L.; Clendaniel, A.; et al. Curcumin-encapsulated nanoparticles as innovative antimicrobial and wound healing agent. Nanomed. Nanotechnol. Biol. Med. 2015, 11, 195-206. [CrossRef] [PubMed]

12. Fadus, M.C.; Lau, C.; Bikhchandani, J.; Lynch, H.T. Curcumin: An age-old anti-inflammatory and anti-neoplastic agent. J. Tradit. Complement. Med. 2017, 7, 339-346. [CrossRef]

13. Chin, K.-Y. The spice for joint inflammation: anti-inflammatory role of curcumin in treating osteoarthritis. DDDT 2016, 10, 3029-3042. [CrossRef]

14. Edwards, R.L.; Luis, P.B.; Varuzza, P.V.; Joseph, A.I.; Presley, S.H.; Chaturvedi, R.; Schneider, C. The anti-inflammatory activity of curcumin is mediated by its oxidative metabolites. J. Biol. Chem. 2017, 292, 21243-21252. [CrossRef]

15. Song, W.; Su, X.; Gregory, D.; Li, W.; Cai, Z.; Zhao, X. Magnetic Alginate/Chitosan Nanoparticles for Targeted Delivery of Curcumin into Human Breast Cancer Cells. Nanomaterials 2018, 8, 907. [CrossRef]

16. Shoba, G.; Joy, D.; Joseph, T.; Majeed, M.; Rajendran, R.; Srinivas, P. Influence of Piperine on the Pharmacokinetics of Curcumin in Animals and Human Volunteers. Planta Med. 1998, 64, 353-356. [CrossRef]

17. Zhang, J.; Tang, Q.; Xu, X.; Li, N. Development and evaluation of a novel phytosome-loaded chitosan microsphere system for curcumin delivery. Int. J. Pharm. 2013, 448, 168-174. [CrossRef] [PubMed]

18. Sari, T.P.; Mann, B.; Kumar, R.; Singh, R.R.B.; Sharma, R.; Bhardwaj, M.; Athira, S. Preparation and characterization of nanoemulsion encapsulating curcumin. Food Hydrocoll. 2015, 43, 540-546. [CrossRef]

19. Montalbán, M.; Coburn, J.; Lozano-Pérez, A.; Cenis, J.; Víllora, G.; Kaplan, D. Production of Curcumin-Loaded Silk Fibroin Nanoparticles for Cancer Therapy. Nanomaterials 2018, 8, 126. [CrossRef] [PubMed]

20. Song, W.; Muthana, M.; Mukherjee, J.; Falconer, R.J.; Biggs, C.A.; Zhao, X. Magnetic-Silk Core-Shell Nanoparticles as Potential Carriers for Targeted Delivery of Curcumin into Human Breast Cancer Cells. Acs Biomater. Sci. Eng. 2017, 3, 1027-1038. [CrossRef]

21. Wang, T.; Ma, X.; Lei, Y.; Luo, Y. Solid lipid nanoparticles coated with cross-linked polymeric double layer for oral delivery of curcumin. Colloids Surf. B Biointerfaces 2016, 148, 1-11. [CrossRef] 
22. Hajj Ali, H.; Michaux, F.; Bouelet Ntsama, I.S.; Durand, P.; Jasniewski, J.; Linder, M. Shea butter solid nanoparticles for curcumin encapsulation: Influence of nanoparticles size on drug loading: Control of shea butter SLN size for curcumin encapsulation. Eur. J. Lipid Sci. Technol. 2016, 118, 1168-1178. [CrossRef]

23. Bhandari, R.; Gupta, P.; Dziubla, T.; Hilt, J.Z. Single step synthesis, characterization and applications of curcumin functionalized iron oxide magnetic nanoparticles. Mater. Sci. Eng. C 2016, 67, 59-64. [CrossRef] [PubMed]

24. Minnelli, C.; Moretti, P.; Fulgenzi, G.; Mariani, P.; Laudadio, E.; Armeni, T.; Galeazzi, R.; Mobbili, G. A Poloxamer-407 modified liposome encapsulating epigallocatechin-3-gallate in the presence of magnesium: Characterization and protective effect against oxidative damage. Int. J. Pharm. 2018, 552, 225-234. [CrossRef]

25. Daraee, H.; Etemadi, A.; Kouhi, M.; Alimirzalu, S.; Akbarzadeh, A. Application of liposomes in medicine and drug delivery. Artif. Cells Nanomed. Biotechnol. 2016, 44, 381-391. [CrossRef]

26. Bozzuto, G.; Molinari, A. Liposomes as nanomedical devices. IJN 2015, 10, 975. [CrossRef] [PubMed]

27. Zhang, W.; Wang, G.; Falconer, J.R.; Baguley, B.C.; Shaw, J.P.; Liu, J.; Xu, H.; See, E.; Sun, J.; Aa, J.; et al. Strategies to Maximize Liposomal Drug Loading for a Poorly Water-soluble Anticancer Drug. Pharm. Res. 2015, 32, 1451-1461. [CrossRef] [PubMed]

28. Nogueira, E.; Gomes, A.C.; Preto, A.; Cavaco-Paulo, A. Design of liposomal formulations for cell targeting. Colloids Surf. B Biointerfaces 2015, 136, 514-526. [CrossRef]

29. Shin, G.H.; Chung, S.K.; Kim, J.T.; Joung, H.J.; Park, H.J. Preparation of Chitosan-Coated Nanoliposomes for Improving the Mucoadhesive Property of Curcumin Using the Ethanol Injection Method. J. Agric. Food Chem. 2013, 61, 11119-11126. [CrossRef]

30. Ahmadi Ashtiani, H.R.; Bishe, P.; Lashgari, N.-A.; Nilforoushzadeh, M.A.; Zare, S. Liposomes in Cosmetics. J. Ski. Stem Cell 2016, 3, e65815. [CrossRef]

31. Emami, S.; Azadmard-Damirchi, S.; Peighambardoust, S.H.; Valizadeh, H.; Hesari, J. Liposomes as carrier vehicles for functional compounds in food sector. J. Exp. Nanosci. 2016, 11, 737-759. [CrossRef]

32. Zylberberg, C.; Matosevic, S. Pharmaceutical liposomal drug delivery: A review of new delivery systems and a look at the regulatory landscape. Drug Deliv. 2016, 23, 3319-3329. [CrossRef]

33. Ma, Y.-H.; Yang, J.; Li, B.; Jiang, Y.-W.; Lu, X.; Chen, Z. Biodegradable and injectable polymer-liposome hydrogel: A promising cell carrier. Polym. Chem. 2016, 7, 2037-2044. [CrossRef]

34. Kadri, R.; Ben Messaoud, G.; Tamayol, A.; Aliakbarian, B.; Zhang, H.Y.; Hasan, M.; Sánchez-González, L.; Arab-Tehrany, E. Preparation and characterization of nanofunctionalized alginate/methacrylated gelatin hybrid hydrogels. Rsc Adv. 2016, 6, 27879-27884. [CrossRef]

35. Lin, C.-C.; Lin, H.-Y.; Chen, H.-C.; Yu, M.-W.; Lee, M.-H. Stability and characterisation of phospholipid-based curcumin-encapsulated microemulsions. Food Chem. 2009, 116, 923-928. [CrossRef]

36. Calder, P.C.; Yaqoob, P. Understanding omega-3 polyunsaturated fatty acids. Postgrad. Med. 2009, 121, 148-157. [CrossRef]

37. Van der Meerena, G.; Tlusty, M.; Metzlerc, A.; Van der Meerend, T. Effects of dietary DHA and EPA on neurogenesis, growth, and survival of juvenile American lobster, Homarus americanus. N. Z. J. Mar. Freshw. Res. 2009, 43, 225-232. [CrossRef]

38. Belhaj, N.; Arab-Tehrany, E.; Linder, M. Oxidative kinetics of salmon oil in bulk and in nanoemulsion stabilized by marine lecithin. Process Biochem. 2010, 45, 187-195. [CrossRef]

39. Gbogouri, G.A.; Linder, M.; Fanni, J.; Parmentier, M. Analysis of lipids extracted from salmon (Salmo salar) heads by commercial proteolytic enzymes. Eur. J. Lipid Sci. Technol. 2006, 108, 766-775. [CrossRef]

40. Kato, Y.; Hosokawa, T.; Hayakawa, E.; Ito, K. Influence of Liposomes on Tryptic Digestion of Insulin. Biol. Pharm. Bull. 1993, 16, 457-461. [CrossRef] [PubMed]

41. Iwanaga, K.; Ono, S.; Narioka, K.; Kakemi, M.; Morimoto, K.; Yamashita, S.; Namba, Y.; Oku, N. Application of surface coated liposomes for oral delivery of peptide: Effects of coating the liposome's surface on the GI transit of insulin. J. Pharm. Sci. 1999, 88, 248-252. [CrossRef]

42. Manconi, M.; Manca, M.L.; Valenti, D.; Escribano, E.; Hillaireau, H.; Fadda, A.M.; Fattal, E. Chitosan and hyaluronan coated liposomes for pulmonary administration of curcumin. Int. J. Pharm. 2017, 525, 203-210. [CrossRef]

43. Manconi, M.; Nácher, A.; Merino, V.; Merino-Sanjuan, M.; Manca, M.L.; Mura, C.; Mura, S.; Fadda, A.M.; Diez-Sales, O. Improving Oral Bioavailability and Pharmacokinetics of Liposomal Metformin by Glycerolphosphate-Chitosan Microcomplexation. Aaps Pharmscitech 2013, 14, 485-496. [CrossRef] 
44. Hasan, M.; Ben Messaoud, G.; Michaux, F.; Tamayol, A.; Kahn, C.J.F.; Belhaj, N.; Linder, M.; Arab-Tehrany, E. Chitosan-coated liposomes encapsulating curcumin: Study of lipid-polysaccharide interactions and nanovesicle behavior. Rsc Adv. 2016, 6, 45290-45304. [CrossRef]

45. Takeuchi, H.; Matsui, Y.; Yamamoto, H.; Kawashima, Y. Mucoadhesive properties of carbopol or chitosan-coated liposomes and their effectiveness in the oral administration of calcitonin to rats. J. Control. Release 2003, 86, 235-242. [CrossRef]

46. Henriksen, I.; Vagen, S.R.; Sande, S.A.; Smistad, G.; Karlsen, J. Interactions between liposomes and chitosan. 2. Effect of selected parameters on aggregation and leakage. Int. J. Pharm. 1997, 146, 193-203. [CrossRef]

47. Takeuchi, H.; Yamamoto, H.; Niwa, T.; Hino, T.; Kawashima, Y. Enteral absorption of insulin in rats from mucoadhesive chitosan-coated liposomes. Pharm. Res. 1996, 13, 896-901. [CrossRef]

48. Kotzé, A.F.; Henrik, L.L.; Thanou, M.; Verhoef, J.C.; de Boer, A.G.; Junginger, H.E. Chitosan and Chitosan Derivatives as Absorption Enhancers for Peptide Drugs Across Mucosal Epithelia. In Bioadhesive Drug Delivery Systems; Drugs and the Pharmaceutical Sciences; CRC Press, Marcel Dekker Inc.: New York, NY, USA, 1999; pp. 341-386.

49. Wajda, R.; Zirkel, J.; Schaffer, T. Increase of bioavailability of coenzyme Q(10) and vitamin E. J. Med. Food 2007, 10, 731-734. [CrossRef]

50. Manca, M.L.; Castangia, I.; Matricardi, P.; Lampis, S.; Fernàndez-Busquets, X.; Fadda, A.M.; Manconi, M. Molecular arrangements and interconnected bilayer formation induced by alcohol or polyalcohol in phospholipid vesicles. Colloids Surf. B Biointerfaces 2014, 117, 360-367. [CrossRef]

51. Zweers, M.L.T.; Grijpma, D.W.; Engbers, G.H.M.; Feijen, J. The preparation of monodisperse biodegradable polyester nanoparticles with a controlled size. J. Biomed. Mater. Res. 2003, 66B, 559-566. [CrossRef] [PubMed]

52. Paolino, D.; Fresta, M.; Sinha, D.; Ferrari, M. Drug delivery systems. In Encyclopedia of Medical Devices and Instrumentation, 2nd ed.; Webester, J.G., Ed.; John Wiley \& Sons, Inc.: New York, NY, USA, 2006; pp. 437-495.

53. Mady, M.M.; Darwish, M.M.; Khalil, S.; Khalil, W.M. Biophysical studies on chitosan-coated liposomes. Eur. Biophys. J. Biophys. Lett. 2009, 38, 1127-1133. [CrossRef] [PubMed]

54. Kuang, G.; Zhang, Z.; Liu, S.; Zhou, D.; Lu, X.; Jing, X.; Huang, Y. Biphasic drug release from electrospun polyblend nanofibers for optimized local cancer treatment. Biomater. Sci. 2018, 6, 324-331. [CrossRef]

55. Preetha, P.; Srinivasa, A.; Pushpalatha, P. Biphasicdrug delivery in controlled release formulations-A REVIEW. Int. J. Pharm. Technol. 2015, 6, 3046-3060.

56. Joraholmen, M.W.; Vanic, Z.; Tho, I.; Skalko-Basnet, N. Chitosan-coated liposomes for topical vaginal therapy: Assuring localized drug effect. Int. J. Pharm. 2014, 472, 94-101. [CrossRef]

57. Maherani, B.; Arab-Tehrany, E.; Kheirolomoom, A.; Geny, D.; Linder, M. Calcein release behavior from liposomal bilayer; influence of physicochemical/mechanical/structural properties of lipids. Biochimie 2013, 95, 2018-2033. [CrossRef]

58. Anal, A.K.; Singh, H. Recent advances in microencapsulation of probiotics for industrial applications and targeted delivery. Trends Food Sci. Technol. 2007, 18, 240-251. [CrossRef]

59. Vandenberg, G.W.; Drolet, C.; Scott, S.L.; de la Noue, J. Factors affecting protein release from alginate-chitosan coacervate microcapsules during production and gastric/intestinal simulation. J. Control. Release 2001, 77, 297-307. [CrossRef]

60. Lee, J.-S.; Kim, H.W.; Chung, D.; Lee, H.G. Catechin-loaded calcium pectinate microparticles reinforced with liposome and hydroxypropylmethylcellulose: Optimization and in vivo antioxidant activity. Food Hydrocoll. 2009, 23, 2226-2233. [CrossRef]

61. Liu, M.; Ishida, Y.; Ebina, Y.; Sasaki, T.; Aida, T. Photolatently modulable hydrogels using unilamellar titania nanosheets as photocatalytic crosslinkers. Nat. Commun. 2013, 4, 2029. [CrossRef]

62. Liu, W.; Ye, A.; Liu, C.; Liu, W.; Singh, H. Structure and integrity of liposomes prepared from milk- or soybean-derived phospholipids during in vitro digestion. Food Res. Int. 2012, 48, 499-506. [CrossRef]

63. Gao, W.W.; Hu, C.M.J.; Fang, R.H.; Zhang, L.F. Liposome-like nanostructures for drug delivery. J. Mater. Chem. B 2013, 1, 6569-6585. [CrossRef] [PubMed]

64. Xing, H.; Tang, L.; Yang, X.J.; Hwang, K.; Wang, W.D.; Yin, Q.; Wong, N.Y.; Dobrucki, L.W.; Yasui, N.; Katzenellenbogen, J.A.; et al. Selective delivery of an anticancer drug with aptamer-functionalized liposomes to breast cancer cells in vitro and in vivo. J. Mater. Chem. B 2013, 1, 5288-5297. [CrossRef]

65. Sugihara, H.; Yamamoto, H.; Kawashima, Y.; Takeuchi, H. Effectiveness of submicronized chitosan-coated liposomes in oral absorption of indomethacin. J. Liposome Res. 2012, 22, 72-79. [CrossRef] 
66. Filipovic-Grcic, J.; Skalko-Basnet, N.; Jalsenjak, I. Mucoadhesive chitosan-coated liposomes: characteristics and stability. J. Microencapsul. 2001, 18,3-12. [CrossRef]

67. Espinal-Ruiz, M.; Parada-Alfonso, F.; Restrepo-Sanchez, L.P.; Narvaez-Cuenca, C.E.; McClements, D.J. Impact of dietary fibers [methyl cellulose, chitosan, and pectin] on digestion of lipids under simulated gastrointestinal conditions. Food Funct. 2014, 5, 3083-3095. [CrossRef]

68. Rodriguez, M.S.; Albertengo, L.E. Interaction between chitosan and oil under stomach and duodenal digestive chemical conditions. Biosci. Biotechnol. Biochem. 2005, 69, 2057-2062. [CrossRef] [PubMed]

69. McConnell, E.L.; Murdan, S.; Basit, A.W. An investigation into the digestion of chitosan (noncrosslinked and crosslinked) by human colonic bacteria. J. Pharm. Sci. 2008, 97, 3820-3829. [CrossRef]

70. Shen, C.R.; Liu, C.L.; Lee, H.P.; Chen, J.K. The Identification and Characterization of Chitotriosidase Activity in Pancreatin from Porcine Pancreas. Molecules 2013, 18, 2978-2987. [CrossRef] [PubMed]

71. Zhang, H.; Alsarra, I.A.; Neau, S.H. An in vitro evaluation of a chitosan-containing multiparticulate system for macromolecule delivery to the colon. Int. J. Pharm. 2002, 239, 197-205. [CrossRef]

72. Kean, T.; Thanou, M. Biodegradation, biodistribution and toxicity of chitosan. Adv. Drug Deliv. Rev. 2010, 62, 3-11. [CrossRef]

73. Linder, M.; Matouba, E.; Fanni, J.; Parmentier, M. Enrichment of salmon oil with n-3 PUFA by lipolysis, filtration and enzymatic re-esterification. Eur. J. Lipid Sci. Technol. (Print) 2002, 104, 455-462. [CrossRef]

74. Ackman, R.G. Remarks on official methods employing boron trifluoride in the preparation of methyl esters of the fatty acids of fish oils. J. Am. Oil Chem. Soc. 1998, 75, 541-545. [CrossRef]

75. Hasan, M.; Latifi, S.; Kahn, C.; Tamayol, A.; Habibey, R.; Passeri, E.; Linder, M.; Arab-Tehrany, E. The Positive Role of Curcumin-Loaded Salmon Nanoliposomes on the Culture of Primary Cortical Neurons. Mar. Drugs 2018, 16, 218. [CrossRef] [PubMed]

76. Aditya, N.P.; Shim, M.; Lee, I.; Lee, Y.; Im, M.H.; Ko, S. Curcumin and Genistein Coloaded Nanostructured Lipid Carriers: in Vitro Digestion and Antiprostate Cancer Activity. J. Agric. Food Chem. 2013, 61, 1878-1883. [CrossRef]

77. Singh, H.; Sarkar, A. Behaviour of protein-stabilised emulsions under various physiological conditions. Adv. Colloid Interface Sci. 2010, 165, 47-57. [CrossRef]

78. Tikekar, R.V.; Pan, Y.J.; Nitin, N. Fate of curcumin encapsulated in silica nanoparticle stabilized Pickering emulsion during storage and simulated digestion. Food Res. Int. 2013, 51, 370-377. [CrossRef]

79. Sun, J.B.; Bi, C.; Chan, H.M.; Sun, S.P.; Zhang, Q.W.; Zheng, Y. Curcumin-loaded solid lipid nanoparticles have prolonged in vitro antitumour activity, cellular uptake and improved in vivo bioavailability. Colloids Surf. B-Biointerfaces 2013, 111, 367-375. [CrossRef]

Sample Availability: Samples of the compounds are not available from the authors.

(C) 2019 by the authors. Licensee MDPI, Basel, Switzerland. This article is an open access article distributed under the terms and conditions of the Creative Commons Attribution (CC BY) license (http://creativecommons.org/licenses/by/4.0/). 